\title{
Assessing the extent and need for disability inclusion in the pharmacy education curriculum in Nigeria
}

\author{
Oluwakorede Adedeji \\ Faculty of pharmaceutical science, University of Ilorin, Nigeria
}

\author{
Keywords \\ Curriculum \\ Disability \\ Inclusion \\ Nigeria \\ Pharmacist \\ Pharmacy student \\ Correspondence \\ Oluwakorede Adedeji \\ Faculty of pharmaceutical sciences \\ University of Ilorin \\ Ilorin \\ Nigeria \\ oluwakorede2017@gmail.com
}

\begin{abstract}
Background: Disability is a prevalent problem in Africa, particularly in Nigeria. The impairment in physical abilities such as hearing, visual, etc. necessitates the need for a specialised approach in the treatment of persons with disabilities by healthcare professionals, including pharmacists. Pharmacists play a central role in the healthcare system among other health professionals because they are usually the first point-of-contact of patients and also play a key role in community surveillance. Aim: In a bid to achieve disability inclusion in Nigeria, it is thus necessary to equip pharmacists with the necessary skills in the care of patients with disabilities, whether intellectual or physical. Method: In this paper, the minimum academic benchmark for awarding the Bachelor of Pharmacy degree (which is the minimum degree that allows one to practice) is well-reviewed and analysed for the presence of any content related to persons with disabilities. Conclusion: Preparing future pharmacists through the pharmacy education curriculum is a useful way to improve the attitude and skills of pharmacy students in the pharmaceutical care of patients with disabilities.
\end{abstract}

\section{Introduction}

Disability affects about $15 \%$ of the World's population, equivalent to over 1 billion people across different countries (WHO, 2021). Nigeria has a population of over 200 million people, and of these, more than 20 million have disabilities (Smith, W.T. et al., 2011). The term "disability" encompasses a number of conditions characterised by impairments in body functions and the inability to carry out normal daily activities independently (WHO, 2021). In reality, people with disabilities are often excluded from enjoying their fundamental rights due to unequal access to healthcare, education, transportation, information and communication facilities (UN, 2017). Persons with disabilities have more unmet health needs than persons without disabilities and require focused attention (WHO, 2021).

In a survey conducted in the states of Kogi and Niger in Nigeria, over $70 \%$ of respondents who are disabled did not have access to health services (Smith N, 2011). Due to challenges of physical, communication and attitudinal barriers, persons with disabilities are often overlooked by the healthcare system, and pharmacists may be contributing to these barriers unknowingly (Wakeham, S., 2017). In the healthcare system particularly in Nigeria, pharmacists have a central role to play, especially in the community settings where they are often the first point of contact for patients. Specific training for taking care of persons with disabilities is therefore essential in ensuring that they get the vital healthcare services which is also part of their fundamental human right.

According to the Article 25 of the United Nations convention on the rights of persons with disabilities, "persons with disabilities shall be provided with specific health services required by them as a result of their disability and shall obtain the same range and quality of health services as others" (UN, 2006). This thus, places a responsibility on pharmacists to obtain the specific skills needed to relate properly with the patients with disabilities. This paper aims to assess the presence, if any, of disability-focused approaches, courses or content in the basic minimum academic standard for the pharmacy curriculum in Nigeria approved by the National Universities Commission (NUC) and Pharmacists Council of Nigeria (PCN) for the 
B. Pharm. degree and the harmonised curriculum for the Doctor of Pharmacy degree (Pharm. D.) training in the Economic Community of West African States (ECOWAS) region; and provide a rationale for the inclusion of disability-specific training courses in the pharmacy education curriculum.

\section{Method}

There are currently two pharmacy first-degrees offered in Nigeria: the Bachelor of Pharmacy (B.Pharm.) and the Doctor of Pharmacy (Pharm. D.). Either of the degrees gives an individual license to practice as a pharmacist in the country. The benchmark and minimum academic standard for the B.Pharm. degree approved by the Pharmacists' Council of Nigeria for pharmacy education are reviewed and analysed for the presence of any content, course, programme, or module related to the care of persons with disabilities or otherwise described in the text. Also, the harmonised curriculum for the Doctor of Pharmacy degree (Pharm. D.) training in the ECOWAS region (the ECOWAS region consists of fifteen countries in West Africa- Benin, Burkina Faso, Cabo Verde, Cote-d'Ivoire, The Gambia, Ghana, Guinea, Guinea-Bissau, Liberia, Mali, Niger, Nigeria, Senegal, Sierra-leone and Togo) is reviewed and analysed likewise for the presence of any content, course, program, or module related to the care of persons with disabilities, or otherwise described in the text.

The following criteria are used in the analysis of the curricula:

1) Identification of persons with disabilities as members of the special population.

2) Presence of any content, course, topic or module, on the care of persons with disabilities.

3) Any mention of the term- 'disabilities', 'disabled persons' or 'persons with disabilities', or as otherwise described.

\section{Results}

There was no mention or referral to persons with disabilities expressly stated in either of the curricula, no identification of persons with disabilities as members of the special population, no course or content specifically for persons with disabilities, nor the mention of the terms-'disabled persons', or 'persons with disabilities'. While the B. Pharm. degree is a five-year degree program and the Pharm. D. is a six-year program, both programs are divided into a series of courses with assigned credits and topics. Although each school may be allowed to augment the curriculum and the overall curriculum may vary from school to school, the absence of a focus on disability health in the minimum academic benchmark depicts a poor disability-inclusion in the Pharmacy education system.

\section{Discussion}

Persons with disabilities often face a lot of barriers in accessing the healthcare services they need. One of such major barriers is the physical/environmental barrier (Smith, W.T. et al., 2011). This barrier entails difficulty in transportation and the navigation to and fro health centres (Ngwena, C. et al., 2014). Another barrier is the attitudinal barrier (Smith W.T. et al., 2011). The insensitivity and lack of respect by healthcare providers towards persons with disabilities have been reported (Smith W.T. et al., 2011). Discrimination and bias pose problems towards taking care of people with disabilities (Smith, W.T. et al., 2011). Communication barriers may also occur when dealing with visually impaired, intellectually impaired or hearing impaired patients.

According to the Nigerian Disability decree 1993, a person with a disability is a person in a condition, either permanent or temporary, "where his or her functional ability is substantially limited, but is not limited to seeing, hearing, thinking, ambulating, climbing, descending, lifting, grasping, rising, any related function or any limitation due to weakness or significantly decreased endurance so that he cannot perform his everyday routine, living and working without significantly increased hardship and vulnerability to everyday obstacles and hazards" (Nigeria - Disability decree, 1993). This same decree states that persons with disabilities shall not be discriminated against and shall have access to health services (Nigeria - Disability decree, 1993). It thus emphasises that persons with disabilities should be able to access health services at a clinic, hospital or pharmacy, without restrictions. Disability inclusion involves understanding the relationship between people and ensuring that people with disabilities have the same rights and access to patients (CDC, 2020). Enabling healthcare professionals to provide the appropriate care to patients with disabilities, requires training and orientation to overcome the attitudinal, communication and physical barriers.

With a growing population of people with disabilities of more than 20 million, it appears that the persons with disabilities are not fully included in the health system. A study investigated the attitude of medical and dental students in Nigeria and reported that students were 
frustrated while taking care of persons with disabilities, and further education would be of benefit to them (Ajuwon, P. et al., 2015). Not only medical and dental students but also pharmacy students can benefit from more education about caring for patients with disabilities. There is a poor mentality towards people with disabilities common in Africa (Ajuwon, P. et al., 2015). In some places, children born with disabilities were accepted for good luck because people thought they were protected by supernatural forces, and in some places, they were totally rejected (Munyi, C.W. et al., 2020). Rather than being seen as a vital part of the population, policymakers and the public sometimes view them as charity or welfare cases (Lang, R., \& Upah, L. 2008). This limits the level of social inclusion attained in these settings and inhibits full recognition of their rights.

The link between poverty and disability could be explained in the sense that the barriers, which includes attitudinal, systemic, environmental that persons with disabilities face, actually intensify the social exclusion and increase the tendency of becoming poor (Ngwena, C. et al., 2014). Breaking down these barriers requires focused training of healthcare students and professionals. Clinical pharmacy and pharmacy practice is the branch of pharmacy that is focused on pharmacist-patient interactions and clinical skills. Incorporating more course content on visual disability, physical disability, hearing disability, intellectual disability and communication disability which forms the five most common disabilities in Nigeria (Smith, W.T. et al., 2011), will greatly help pharmacists and pharmacy students to relate better to this special group and satisfy their health needs. Reducing attitudinal barriers by enlightening students on the prevalence, type of disabilities, and the common misconceptions about having disabilities; Inhibiting communication barriers by providing special patient interaction and communication skills; and enhancing environmental access through building regulations that enable easy access. Recognising interpersonal bias can help pharmacists relate better with these patients (Groce, N. et al., 2011). The identification of disability as a culture and the implementation of cultural competency in pharmacy education may enable better interpersonal relations between pharmacists and patients (Smith, W.T. et al., 2011).

\section{Conclusion}

Patients with disabilities often face a lot of barriers in accessing health services. Recognising these barriers and eliminating the bias and poor mentality is necessary for achieving disability inclusion. It can therefore be concluded that the inclusion of disability within the pharmacy curricula is poor and requires urgent efforts in the revision of the curricula. The curricula should be revised to reiterate the identification of patients with disabilities as a special group and the need to communicate and interact with them specially.

\section{References}

Ajuwon, P., Afolabi Lesi, F., Odukoya, O. \& Melia, C. (2015). Attitudes of medical students toward disabilities in Nigeria. International Journal on Disability and Human Development, 14(2), 131-140. https://doi.org/10.1515/ijdhd-2014-0017

Centre for Disease Control and Prevention (2020). Disability and Health Overview. Available at:

https://www.cdc.gov/ncbddd/disabilityandhealth/disability. html

Groce, N., Kett, M., Lang, R., \& Trani, J.F. (2011). Disability and poverty: The need for a more nuanced understanding of implications for development policy and practice. Third World Quarterly, 32(8), 1493-1513. https://doi.org/10.1080/01436597.2011.604520

Lang, R., \& Upah, L. (2008). Scoping study: Disability issues in Nigeria. Available at: https://afri-can.org/wpcontent/uploads/2016/04/DISABILITY-STUDY-DFID_UG.REPORT-2009.pdf

Munyi, C. W. (2012). Past and present perceptions towards disability: A historical perspective. Disability Studies Quarterly, 32(2). https://doi.org/10.18061/dsq.v32i2.3197

Ngwena, C., Grobbelaar-du Plessis, I., Combrinck, H., \& Kamga, S. D. (Eds.). (2014). African Disability Rights Yearbook Volume 1 2013. Pretoria University Law Press

Nigeria - Disability decree ( 1993). Available at: https://dredf.org/legal-advocacy/international-disabilityrights/international-laws/nigeria-disability-decree/

Smith, N. (2011). The face of disability in Nigeria: A disability survey in Kogi and Niger States. Disability, CBR \& Inclusive Development, 22(1), 35-47.

https://doi.org/10.5463/dcid.v22i1.11

Smith, W.T., Roth, J.J., Okoro, O., Kimberlin, C., \& Odedina, F. T. (2011). Disability in cultural competency pharmacy education. American Journal of Pharmaceutical Education, 75(2). https://doi.org/10.5688/ajpe75226

United Nations (2006). Convention on the rights of persons with disabilities. Available at:

https://www.un.org/disabilities/documents/convention/co nvoptprot-e.pdf

United Nations (2017). Division for Social Policy Development (DSPD), Department of Economic and Social Affairs (DESA). Toolkit on Disability for Africa: Introducing the United Nations Convention on the rights of persons with disabilities. Available at: 
https://www.un.org/esa/socdev/documents/disability/Tool kit/Intro-UN-CRPD.pdf

Wakeham, S., Heung, S., Lee, J., \& Sadowski, C.A. (2017).

Beyond equality: Providing equitable care for persons with disabilities. Canadian Pharmacists Journal : $C P J=$ Revue des pharmaciens du Canada : RPC, 150(4), 251-258. https://doi.org/10.1177/1715163517710957

World Health Organization Regional Office for Africa (2021). Disabilities. Available at: https://www.afro.who.int/healthtopics/disabilities 